\section{A new horizon for the medical device sector in South Africa}

To the Editor: Access to high-quality, safe and appropriate priority medical devices is becoming the bedrock of delivery of effective and efficient healthcare across the world. The use of medical devices impacts on the continuum of care under the universal health coverage strategy. However, the decision-making process relating to commissioning, maintenance and decommissioning of medical devices, often taken without evidence, results in poor service delivery, particularly in developing countries. The World Health Organization baseline country survey ${ }^{[1]}$ provides a global reference on health technologies, and particularly on the availability of specific medical devices, policies, guidelines, standards and services. It is necessary to develop country-specific case studies to elaborate on these reports and to share road maps from the progress made in different countries.

A qualitative analysis of the various processes currently undertaken in South Africa (SA) reveals that medical devices and the medical diagnostic sector are estimated to be worth US $\$ 2.5$ - US $\$ 3$ billion. Although the SA pharmaceutical sector is subject to comprehensive regulation, current knowledge of the medical device sector is deficient. It is noted that the absence of a regulatory system combined with a 'multi-channel' system of procurement of medical devices (between the public and private systems as well as within the public system across different provinces) contribute to this problem. Only a few medical devices (such as radiological equipment) are subject to mandatory quality standards, resulting in importation of sub-standard products. Lack of skilled manpower and an integrated approach to management of medical devices, as well as the absence of a regulatory environment, are major challenges. A South African health product regulatory authority is currently being established to address the gap. ${ }^{[2]}$ A detailed study is being planned to document the current regulation and legislation, market funding and financing. ${ }^{[3]}$ In addition, another project is exploring the possibility of setting up a South African health regulatory training institute to address the shortage of skills in regulation. ${ }^{[4]}$ A multi-disciplinary team of practitioners (consisting of engineers, clinicians and health economists) will be required to lead decision making in health systems. Training in health technology assessment could contribute to their expertise in the interdisciplinary work of medical device management.

SA is currently in the process of introducing National Health Insurance to improve provision of universal health coverage. Effective and efficient use of medical devices would assist in this process.

\section{Debjani B Mueller}

Faculty of Health Sciences, University of the Witwatersrand, Johannesburg, South Africa; Center for Research on Health Economics, Social and Health Care Management (CREMS), University Carlo Cattaneo (LIUC), Castellanza Varese, Italy; CMeRC Health Technology Assessment Unit, Johannesburg, South Africa debjani.mueller@wits.ac.za

\section{Moreshnee Govender}

Department of Community Health, Faculty of Health Sciences, University of the Witwatersrand, Johannesburg, South Africa; CMeRC Health Technology Assessment Unit, Johannesburg, South Africa

\section{Debashis Basu}

Department of Community Health, Charlotte Maxeke Johannesburg Academic Hospital and Faculty of Health Sciences, University of the Witwatersrand, Johannesburg, South Africa; CMeRC Health Technology Assessment Unit, Johannesburg, South Africa

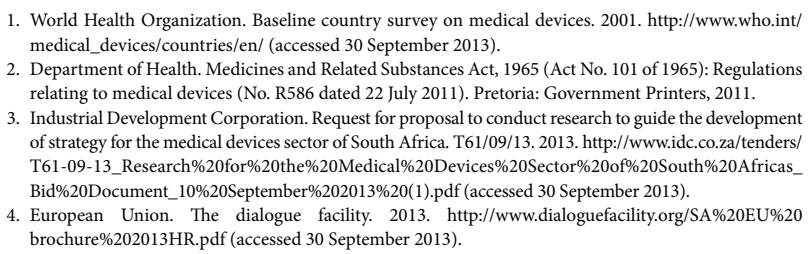

World Health Organization. Baseline country survey on medical devices. 2001. http://www.who.int/ medical_devices/countries/en/ (accessed 30 September 2013).

2. Department of Health. Medicines and Related Substances Act, 1965 (Act No. 101 of 1965): Regulations relating to medical devices (No. R586 dated 22 July 2011). Pretoria: Government Printers, 2011.

3. Industrial Development Corporation. Request for proposal to conduct research to guide the development of strategy for the medical devices sector of South Africa. T61/09/13. 2013. http://www.idc.co.za/tenders/ T61-09-13_Research\%20for\%20the\%20Medical\%20Devices $\% 20$ Sector\%20 of\%20South\%20Africas_ Bid\%20Document_10\%20September\%202013\%20(1).pdf (accessed 30 September 2013).

4. European Union. The dialogue facility. 2013. http://www.dialoguefacility.org/SA\%20EU\%20 brochure\%202013HR.pdf (accessed 30 September 2013).

S Afr Med J 2014;104(5):326. DOI:10.7196/SAMJ.7611 